\title{
Vocal and non-vocal behavior interact differently in territorial strategies of two sympatric Rallidae species
}

\author{
Jan Jedlikowski ${ }^{1}\left[\right.$ Marcin Polak ${ }^{2} \cdot$ Mattia Brambilla ${ }^{3,4} \cdot$ Paweł Rę $^{5}$
}

Received: 9 May 2020 / Revised: 20 June 2020 / Accepted: 1 August 2020 / Published online: 14 August 2020

(c) The Author(s) 2020

\begin{abstract}
Territorial interactions between animals involve correlated signaling and direct actions, yet different species vary in how they utilize each component. In theory, opponents should balance costs and benefits of territorial interactions, and restrict their conflicts to signaling when physical interactions are likely to escalate to serious injuries. We tested these predictions by simulating territorial intrusions in two sympatric non-passerine bird species: the Water Rail (Rallus aquaticus) and Little Crake (Zapornia parva). These species differ physically and behaviorally, with the former being larger and more aggressive, and known to cause serious or fatal injury to other birds. We measured vocal signals and approach behavior of each species towards conspecific and heterospecific playbacks (Little Grebe Tachybaptus ruficollis). Both species increased their calling rate in response to their conspecific treatments; however, Water Rails produced louder call variants, decreased the fundamental frequency of their calls, and produced more duets. In contrast, Little Crakes did not modify the acoustic structure of their calls and rarely participated in duetting. In addition to differences in vocal behavior, Water Rails approached the speaker exceptionally, whereas Little Crakes did it regularly. We conclude that while settling territorial conflicts, Water Rails utilized a purely signaling strategy involving reliable vocal signals and thus the avoidance of direct actions, whereas Little Crakes relied primarily on direct actions.
\end{abstract}

Keywords Aggressiveness · Rallus aquaticus · Territorial interaction · Vocal duetting · Vocal repertoire · Zapornia parva

\section{Zusammenfassung}

Vokales und nicht-vokales Verhalten bestimmen in unterschiedlicher Weise das Territorialverhalten zweier sympatrischer Rallen

Territoriale Interaktionen zwischen Tieren beinhalten aufeinander abgestimmte Signale und direkte Auseinandersetzungen, wobei jedoch die verschiedenen Arten in der Nutzung der einzelnen Komponenten variieren. Theoretisch sollten Kontrahenten die Kosten und Nutzen der territorialen Interaktionen gegeneinander abwägen und ihre Konflikte auf Signalgebung beschränken, wenn physische Interaktionen mit großer Wahrscheinlichkeit eskalieren und somit zu schweren Verletzungen führen würden. Wir untersuchten diese Vorhersagen, indem wir territoriales Eindringen bei zwei sympatrischen

Communicated by F. Bairlein.

Electronic supplementary material The online version of this article (https://doi.org/10.1007/s10336-020-01808-2) contains supplementary material, which is available to authorized users.

Jan Jedlikowski

janjedlikowski@biol.uw.edu.pl

1 Faculty of Biology, Biological and Chemical Research Centre, University of Warsaw, Żwirki i Wigury 101, 02-089 Warsaw, Poland

2 Department of Zoology and Nature Protection, Institute of Biological Sciences, Maria Curie-Skłodowska University, Akademicka 19, 20-033 Lublin, Poland
3 Settore Biodiversità e Aree protette, Fondazione Lombardia Per L'Ambiente, Largo 10 luglio 1976 1, 20822 Seveso, MB, Italy

4 Sezione Zoologia dei Vertebrati, Museo Delle Scienze, Corso della Scienza e del Lavoro 3, 38123 Trento, Italy

5 Department of Behavioural Ecology, Institute of Environmental Biology, Faculty of Biology, Adam Mickiewicz University, Umultowska 89, 61-614 Poznan, Poland 
Nichtsingvogelarten simulierten: der Wasserralle (Rallus aquaticus) und dem Kleinsumpfhuhn (Zapornia parva). Diese Arten unterscheiden sich physisch und im Verhalten, wobei erstere größer und aggressiver ist und bekanntermaßen bei anderen Vögeln schwere oder tödliche Verletzungen verursacht. Wir nahmen Rufsignale und Annäherungsverhalten jeder Art beim Abspielen von konspezifischen und heterospezifischen Playbacks (Zwergtaucher Tachybaptus ruficollis) auf. Beide Arten erhöhten ihre Ruffrequenz als Reaktion auf das Abspielen arteigener Rufe. Jedoch zeigte die Wasserralle eine höhere Rufvariation, verringerte die Grundfrequenz ihrer Rufe und begannen mehr Duette. Im Gegensatz dazu änderten Kleinsumpfhühner die akustische Struktur ihrer Rufe nicht und nahmen selten an Duetten teil. Zusätzlich zu den Unterschieden im Rufverhalten näherten sich die Wasserrallen selten dem Lautsprecher, während Kleinsumpfhühner sich regelmäßig annäherten. Wir schließen daraus, dass Wasserrallen für das Verhindern von Territorialkonflikten eine reine auf verlässliche Rufsignale basierende Strategie verwandten und damit direkte Auseinandersetzungen vermieden, während sich Kleinsumpfhühner in erster Linie auf letztere verließen.

\section{Introduction}

Negotiation of territorial boundaries is a costly and complex process (Vehrencamp et al. 2014). The taking and maintenance of a territory can be time-consuming, energetically demanding, and risky (Copenhaver and Ewald 1980; Low 2006). And while the goals of territorial rivals are divergent, they do share common goals of minimizing cost and avoiding injury. Therefore, animals are expected to act strategically in an effort to balance costs and potential benefits under conditions of uncertainty (Searcy and Nowicki 2005).

Species' territorial strategies involve syndromes of signals and direct actions (Sih et al. 2004). The signaling component is the first line of defense and aims to minimize cost and uncertainty (McGregor 1993; Bradbury and Vehrencamp 2011), whereas the direct or non-signaling component, such as attack or exploration, involves direct physical actions aimed at taking or maintaining territory (Kaiser et al. 2019). Species-wide and in the long-term, territorial intrusions prompt specific combinations of both components. However, individual decisions and tactics are influenced by a combination of factors including resource-holding potential, experience, resource value, and motivational state (Hurd 2006; Arnott and Elwood 2008; Kasumovic et al. 2009; Bergman et al. 2010).

In birds, most territorial strategies combine vocal signaling with some form of direct aggression, yet taxonomic groups differ substantially. Vocal signaling of songbirds, for example, has a complex, hierarchical, and learned structure, which is used sequentially and flexibly in parallel with conflict escalation (Searcy and Beecher 2009; Vehrencamp et al. 2014). Consequently, direct aggression among songbirds is limited and rudimentary in form (e.g., Krebs 1982; Searcy et al. 2006; de Kort et al. 2009; Ali and Anderson 2018). Social interactions among vocally non-learning species are equally complex (Marler 2004). However, innate programming and limited functionality of the vocal apparatus create a constraint that must be counterbalanced. Many non-passerines rely on threat postures and low-frequency growling calls, which are more reminiscent of mammalian behavior than passerine behavior (e.g., Craig 1977; Hand 1986; Hansen 1986; Waas 1991; Pandolfi and D’Astore 1992; Côté 2000). This information suggests that the diversity of territorial strategies among different species appears to have deep evolutionary roots.

In addition to phylogenetic differences, the inherent risk of the interaction, i.e., unpredictability and irreversibility of consequences, likely determines the signaling and nonsignaling behaviors used by the species. Predators, such as raptors or owls, have deadly weapons at their disposal for hunting prey. However, because the use of these weapons can be fatal, predators typically avoid fighting with conspecifics (Garcelon 1990). Bird species do not usually have adaptations specifically for fighting, but long, sharp beaks or strong legs are prevalent among families such as Ardeidae, Gaviidae, Laridae, Struthionidae, or Rallidae, which could result in serious injury during a conflict (Pierotti and Annett 1994; Jemieson 1997; Piper et al. 2008). Therefore, as long as the risk is high, rivals should rarely approach each other during territorial disputes, but should instead rely on long-range signaling or ritualization (Enquist and Leimar 1990), as observed in many raptors and owls (e.g., Temeles 1990; Hansen 1986; Penteriani et al. 2007; Severinghaus 2008). Nevertheless, fights are undoubtedly the most definite solution of any conflict and, as long as it is not necessary to avoid them, fighting should make an inherent part of any territorial strategy. Fighting should not be exchanged with any purely signaling strategy (Enquist 1985), as shown even for many small passerines (Searcy et al. 2013).

Vocal systems of non-passerines are evolutionarily limited, but they can still effectively substitute direct aggression. Some birds, such as crakes, modify the temporal distribution of their calls or switch between loud and soft calls when interacting with intruders (Ręk and Osiejuk 2011, 2013; Ręk 2015). However, such signals have motivational character and short duty cycles, and so they accompany direct actions rather than a substitute for them (Ręk and Osiejuk 2011, 
2013; Ręk 2015). By contrast, because vocal production is subject to morphological, physiological, and neural mechanistic constraints (Podos and Nowicki 2004), some acoustic parameters can provide information about the sender's inherent qualities. For example, the fundamental frequency of vocalizations is generally negatively related to body size (Goller and Riede 2013; Riede et al. 2016), yet the reliability of this relationship depends on the mechanism used. Birds use several mechanisms to produce low-frequency sounds, either open or closed-mouthed (Fitch 1999; Suthers 1990). The close-mouthed mechanism evolved independently in several lineages of non-passerines and generates conditions that favor low-frequency sounds so that they can produce lower frequencies than vocalizations into an open vocal tract of similar size (Riede et al. 2016), suggesting that reliable signaling with low-frequency might have only evolved in some species.

We studied territorial behavior and communication of two sympatric non-passerine species: Water Rail (Rallus aquaticus) and Little Crake (Zapornia parva). Both Rallidae species are cryptic, socially-monogamous for at least one breeding season, and occupy similar wetland habitats (Taylor 1998; Jedlikowski et al. 2016). They produce simple repertoires of innately programmed calls, with males and females having the same repertoire in addition to sexspecific courtship calls (Cramp and Simmons 1980). In both species, partners cooperate in territorial defense and breeding, and facultatively in vocal duetting (Bengtson 1967; Cramp and Simmons 1980; Dittberner and Dittberner 1990; Jedlikowski and Brambilla 2017). However, Water Rails are three times heavier, have beaks that are twice as long, and are more aggressive than Little Crakes (Cramp and Simmons 1980). Water Rails have been observed attacking conspecifics during territory establishment in pre-nesting and wintering periods (Bengtson 1967; King 1980; Taylor 1998; Ciach 2007), and chasing and killing other bird species with their beaks (Barry 1995; Steiof 1999; Ciach 2007). Little Crakes defend breeding territories against conspecifics, but they are not offensive and seem to tolerate other marsh nesting species unless directly threatened (Cramp and Simmons 1980; Dittberner and Dittberner 1990).

The overall goal of this study was to test whether the behavioral and morphological differences between these similar species is related to their use of specific territorial defense strategies during breeding. To test this, we carried out a playback experiment and observed the birds' behavior and signaling responses. Our predictions were that the Water Rail, as the species able to cause serious injury to other birds, would be less likely to act aggressively during interactions with conspecifics than the Little Crake. Additionally, Water Rails would display more vocal signaling than the Little Crake to compensate for the lack of direct aggression.

\section{Methods}

\section{Study area and species}

The study was carried out in the central part of the Mazurian Lakeland (NE Poland) in 2016 and 2017. We collected data at 32 small mid-field water bodies distributed near Łuknajno Lake between $53^{\circ} 47^{\prime}-53^{\circ} 53^{\prime} \mathrm{N}$ and $21^{\circ} 33^{\prime}-21^{\circ} 44^{\prime} \mathrm{E}$. The total area of the water bodies varied from 0.18 to 5.75 ha (mean $=2.08$ ), and all of them were overgrown by emergent vegetation (see Jedlikowski et al. 2016 for detailed description).

Water Rails and Little Crakes occupied the study area during the breeding season (April-September); yet, the distribution of territories varied seasonally depending on water level and availability of dense emergent vegetation. During the study period, we identified $47-65$ breeding pairs of the Water Rail and 20-24 breeding pairs of the Little Crake. According to telemetry measurements, the areas occupied by breeding pairs varied from 325 to $1600 \mathrm{~m}^{2}$ (mean $\left.1105.8 \mathrm{~m}^{2} \pm 281.3 \mathrm{SE}, n=4\right)$ for the Water Rail and from 248 to $1225 \mathrm{~m}^{2}$ (mean $793.0 \mathrm{~m}^{2} \pm 149.7 \mathrm{SE}, n=7$ ) for the Little Crake (Jedlikowski and Brambilla 2017). The minimum distances between nests were $52 \mathrm{~m}$ and $28 \mathrm{~m}$, respectively (Jedlikowski and Brambilla 2017).

\section{Playback experiment}

To examine the territorial behavior of Water Rails and Little Crakes, we carried out the playback experiment between May and July of 2016 and 2017. The experiment used acoustic playback that aimed at imitating territorial intrusion. Before the experiment, we located all nests of the subject pairs and mapped their territories by monitoring each water body at least once a week from the time the birds arrived until the end of the breeding season. To reduce variation in bird response within breeding stages, only incubating breeding pairs were tested.

The playback experiment was carried out on 26 pairs of the Water Rail and 24 pairs of the Little Crake, all subjected to multiple treatments. To minimize the chance of testing the same individuals twice, we performed playbacks at different water bodies each year. We captured and individually colorbanded 35 Little Crakes from 23 pairs and four Water Rails from four pairs. We did not find any territory changes within a breeding season and there was a low return rate between seasons (four crakes-11\%).

The design of the experiment was similar for both species. Each focal pair was subjected to two treatments: a conspecific treatment (Little Crake or Water Rail) and a heterospecific treatment (control-Little Grebe Tachybaptus ruficollis). The Little Grebe was used as a control because 
it regularly co-occurred with rallids within the studied area, and our former observations suggested that it would be neutral for the focal species. Little Grebes nest mainly in the patches of the Phragmites australis (Jedlikowski, unpubl. data) and collect food (benthonic invertebrates, amphibians, and small fish) diving at the open water area (Ceccobelli and Battisti 2010). In contrast, both rallids nest mainly in dense patches of Carex spp. and Typha spp. (Jedlikowski et al. 2016), and forage on invertebrates collected from the emergent vegetation or water surface (Taylor 1998). Treatments were carried out 60-90 min apart in a balanced order. For the conspecific treatment, we used male-specific calls produced during territory formation at the beginning of the breeding season (Polak 2005). In both rail species, these calls are uttered by solitary males in long series (Cramp and Simmons 1980; Polak 2005; Supplementary file1). For the control treatment, we used territorial calls of the Little Grebe (Supplementary file1). The conspecific stimuli were selected from a sample of nine Water Rails and six Little Crakes, whereas the heterospecific stimuli were selected from vocalizations of eight Little Grebes. The playback stimuli were thus not fully replicated among experimental pairs, but used 2-3 times each for the Water Rail treatments, four times each for the Little Crake treatments, and 3-4 times each for the Little Grebe treatments.

Playback stimuli were prepared from high-quality recordings. For each stimulus, we recorded a few minutes of the spontaneous calling of one individual, trimmed the recording to 1-min long uninterrupted fragment, and replicated this fragment six times. Call rates within the stimuli were natural: $130 \pm 18$ calls min $^{-1}$ for Water Rails, $117 \pm 17$ calls $\mathrm{min}^{-1}$ for Little Crakes, and $169 \pm 25$ calls $\mathrm{min}^{-1}$ for Little Grebes (Jedlikowski unpubl. data). The recordings were made in the Łuknajno Lake (1-9 km from studied areas) in April of each year from a distance of 10-15 $\mathrm{m}$ from the subjects. Recordings were made with a Marantz PMD 661 MKII recorder and a Sennheiser ME67 unidirectional microphone stored in wav format using a sample rate of $48 \mathrm{kHz}$ and a resolution of 16 bits. Recordings were edited using the Raven Pro 1.5 software (Bioacoustics Research Program 2014). All call samples were high-pass filtered $(100 \mathrm{~Hz})$ to remove low-frequency background noise.

\section{Field methods}

Treatments had identical timelines and execution. Treatments were carried out between 08:00-11:00 and 16:00-22:00 (local time). Each treatment lasted $15 \mathrm{~min}$ and consisted of three phases: 3-min of playback and 2-min of silence, 2-min of playback and 3-min of silence, and 1-min of playback and 4-min of silence. Playbacks were broadcast at $60 \mathrm{~dB}$ Sound Pressure Level (SPL at $5 \mathrm{~m}$ ) for Water Rails, 55 dB SPL for Little Crakes, and 58 dB SPL for Little
Grebes. These levels correspond with natural amplitudes measured by the authors with a CHY 650 Sound Level Meter (58-65 dB SPL from six Water Rails, 51-58 dB SPL from four Little Crakes, 55-61 dB SPL from five Little Grebes; at around $5 \mathrm{~m}$ ). For playbacks, we used the Philips GoGEAR player connected to two loudspeakers (Pignose Legendary 7-100 Portable Amp). The loudspeakers were deployed at least $1 \mathrm{~h}$ beforehand on floating platforms within a breeding pair territory and hidden with dense vegetation $10 \mathrm{~m}$ from their active nest in a random direction. We used this distance to mirror the area usually defended by both species (Jedlikowski and Brambilla 2017). The vocal reaction of the birds was recorded using a digital recorder (Marantz PMD 661 MKII) coupled with a unidirectional microphone (Sennheiser ME67) set up on the tripod 15-20 m from the nest ( $48 \mathrm{kHz}$ and 16 bit PCM files). The non-vocal behavior was recorded by two camouflaged digital wildlife observation cameras (Bushnell NatureView Cam HD) located $1.5 \mathrm{~m}$ in front of each loudspeaker. The cameras were movementsensitive and able to record in low-light conditions without disturbing the birds (invisible infrared flash).

\section{Responses to treatments}

We started by describing the structure and production of natural vocalizations to assess the level of motivation of the subjects. During the incubation period, birds mainly remained silent and used territorial calls only when disturbed (Cramp and Simmons 1980; Jedlikowski unpubl. data). This suggests that the calls recorded during treatments were prompted by our stimuli. We counted calls (discrete vocalizations), classified them into particular variants (Water Rail) or types (Little Crake), and assigned them as solos or duets (Figs. 1, 2). Then, we visually scanned spectrograms of the experimental recordings using Raven Pro 1.5 software. The process of classification was straightforward because the same categories were present in multiple individuals, and no call could be assigned to more than one category (Figs. 1, 2; see also Results). However, the terms variant and type were used only for precision; specifically to reflect the fact that Water Rail calls are formed according to one general acoustic design, whereas calls of Little Crakes appear more polymorphic (Figs. 1,2).

Furthermore, we measured the acoustic parameters of calls produced in response to treatments (see Table 1 for a list and Figs. 1, 2 for visualization). We only measured calls that did not have strong background noise $(n=133$ for the Water Rail and $n=244$ for the Little Crake). The measurements were taken from sonograms using Raven Pro 1.5 software. To maximize precision, we used different settings of the sonogram window for spectral and temporal measures (Table 1), and these were: 'Window: Hann, 2048 samples; $3 \mathrm{~dB}$ bandwidth: $67.4 \mathrm{~Hz}$; frame overlap 50\%; DFT Size: 

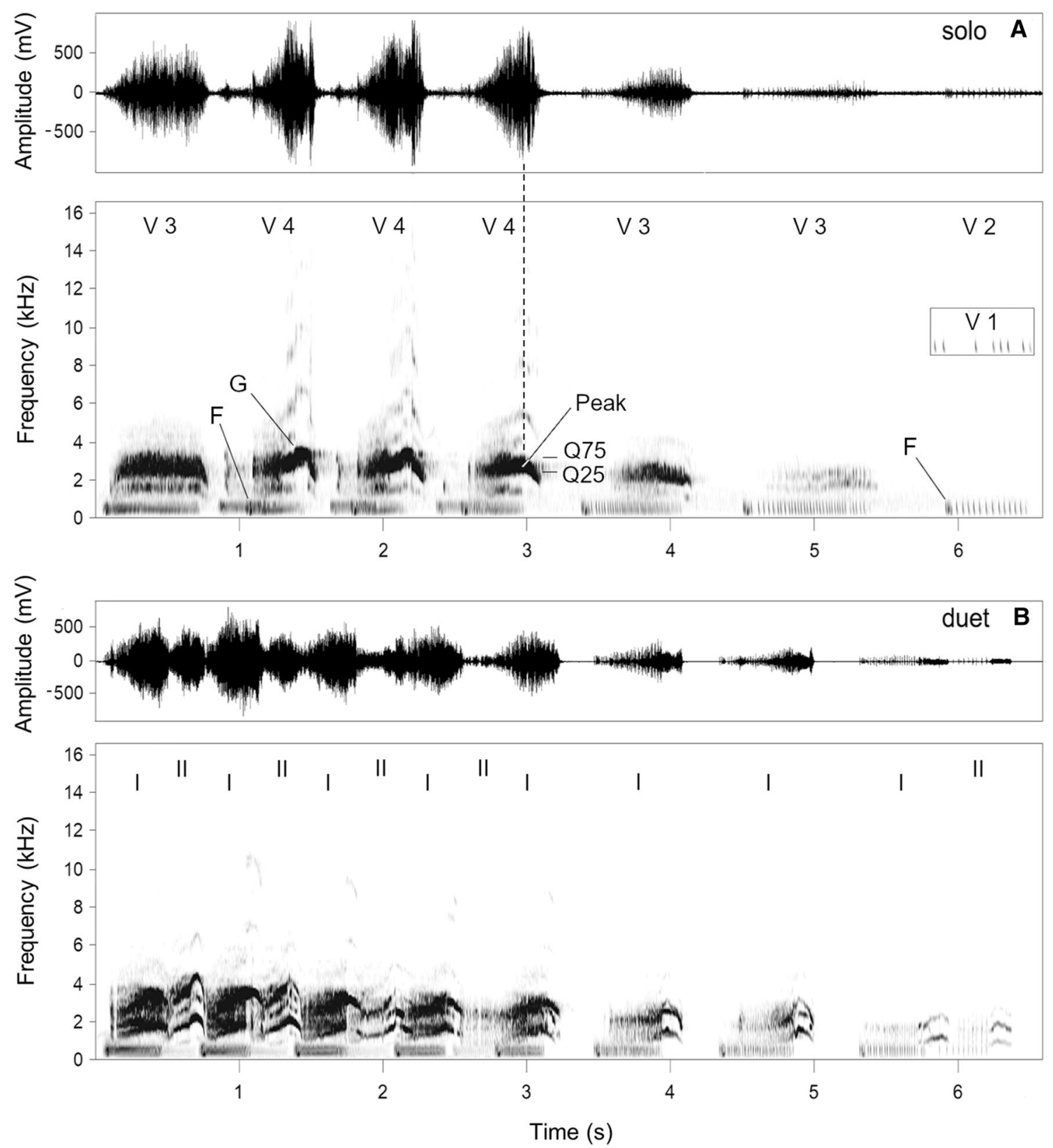

Fig. 1 Spectrograms and oscillograms of Water Rail growling-squealing calls. Typically, calls are produced in series solo (a) or in duets (b). A series may consist only of disorganized pulses (V1) or contain one to three distinct call variants: soft growling calls (V2), muted

8192 samples' for spectral measures and 'Window: Hann, 512 samples; $3 \mathrm{~dB}$ bandwidth: $270 \mathrm{~Hz}$; frame overlap 50\%; DFT Size: 512 samples' for temporal measures. We assigned vocal responses to the male-female pairs rather than to individuals because both birds typically responded to the playback by calling sequentially or by producing duets. In most cases, it was impossible to identify the sex of the caller. Nevertheless, we could easily deduce that two birds were calling because calls were produced one after another from squealing calls (V3) and harsh squealing calls (V4). At b I and II indicate calls produced by two birds in a duet. For the original recording, see Supplementary file2 or https://www.animalsoundarchive.org

two locations and confirm it by inspecting spectrograms. Recordings from our camera traps and earlier observations supported this approach.

Finally, we quantified non-vocal responses by recording when birds approached the speaker and the duration of time the birds spent in the vicinity of the speaker. To do this, we analyzed video recordings from the camera traps (1080p Full HD). Birds that came within $1.5 \mathrm{~m}$ were noted as approaching the speaker. The duration of time spent within $1.5 \mathrm{~m}$ 

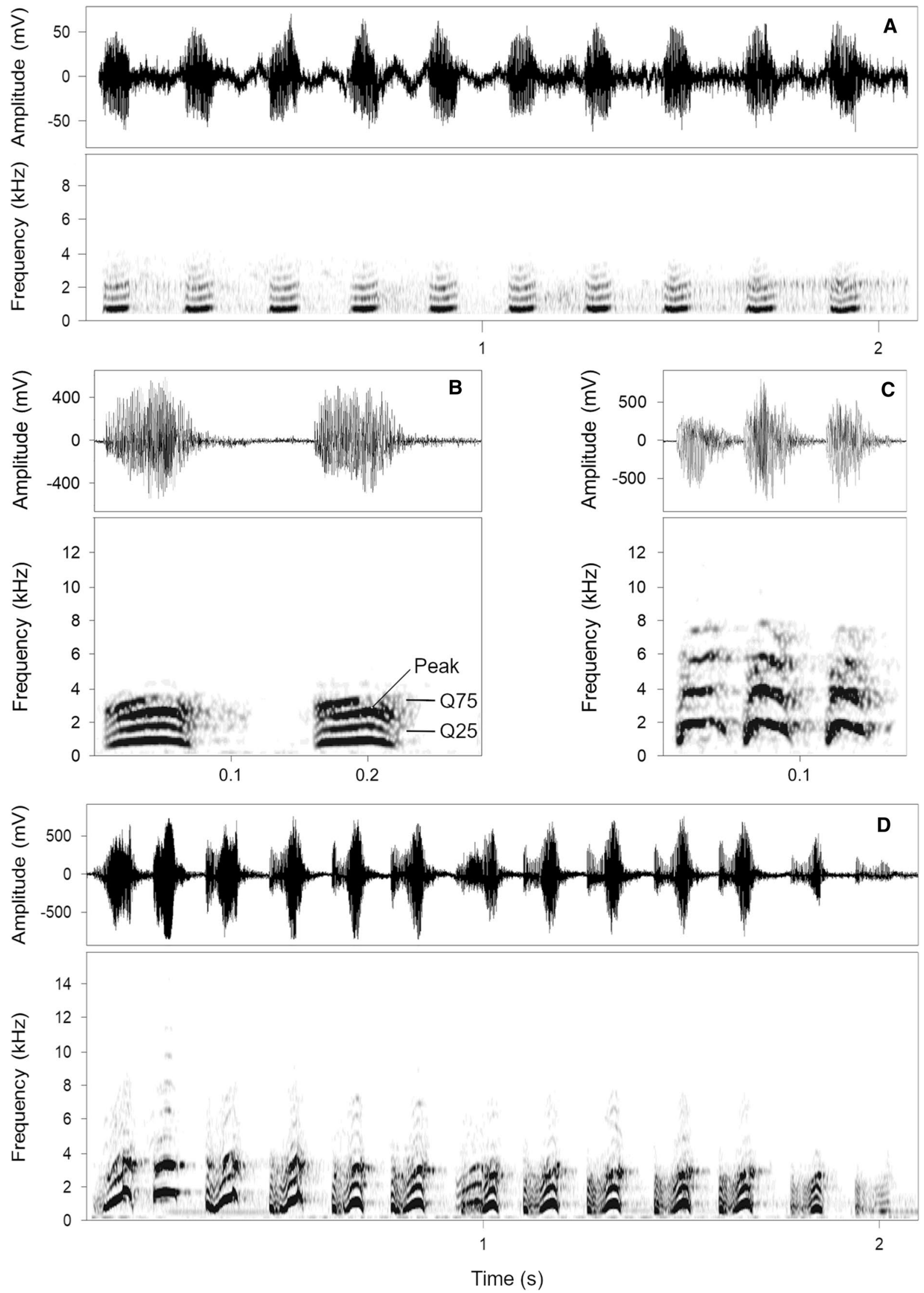
4Fig. 2 Spectrograms and oscillograms of Little Crake calls. We identified four general types of calls: a chatting, b doublet, $\mathbf{c}$ peaks, and d trill. For the original recording, see Supplementary file3 or https:// www.animalsoundarchive.org

from the speaker (in seconds) was measured. Recordings were assigned to individuals through visual inspection on the video recordings because both species can be sexed visually.

\section{Statistical analysis}

We used generalized linear mixed models to compare the responses of birds to the treatments. This procedure is appropriate for repeated measures data, which enabled us to account for responses of the male and female within a pair and responses of the same pairs to multiple treatments, considering their order. The procedure is also appropriate for non-normally distributed data. Within this procedure, we included the recording ID as a random effect to emulate the randomness in playbacks. This approach is commonly used to account for pseudoreplication in the data (Millar and Anderson 2004). We analyzed the responses of each species separately using different response variables based on the particular behaviors that were observed. To compare the numbers of calls and acoustic parameters between treatments, we fitted the variables using the normal distribution. Because we could not always recognize individuals within a pair, we compared pairs (random effect) in terms of the vocal response, controlling for the within-pair variance. We found that contrary to the significant overall variance (within + between pairs), the within-pair variance was at least 10-times smaller and never significant, suggesting that either the same individuals responded during both treatments or that situations in which the male responded to one treatment and female to another were unlikely and did not contribute significantly to results. In the analyses with acoustic parameters, we additionally used the call variant/ type and the interaction treatment-call variant/type as fixed effects. To compare non-vocal responses, we fitted the data using a binomial distribution with logit link function for the approaching behavior and normal distribution to analyze the time spent near the speaker. Because the approaching birds were video recorded and identified, we compared individuals for their non-vocal response, by adding individual identities as the random effect in the models. In addition to treatments, we controlled initially for the time of the experiment (morning-evening) in all analyses. However, this factor was never significant, and it was removed from the final models. In all analyses, Fisher's LSD method was used to create confidence intervals for differences between treatment means. We used the SPSS v. 25 software (IBM, Armonk, NY, U.S.A.) for statistical analyses. All $P$ values were two-tailed and, if not stated otherwise, means \pm SE are given.

\section{Results}

\section{Structure and production of vocalizations}

Water Rails responded to treatments with a characteristic series of growling-squealing calls (Fig. 1). Each series contained $1-12$ calls $(3.6 \pm 0.14, n=115)$ that could be assigned to four variants. The acoustically simplest variants consisted only of the $F$-component. The $F$-component makes a soft, amplitude modulated, growling sound, which can be produced as a disorganized series of pulses (Fig. 1, variant 1) or in a trilled like fashion (Fig. 1, variant 2). It is produced when the bird's beak and nares are closed, and the air is pumped back and forth to the crop (Supplementary file4 and 5). The remaining variants arise when the bird opens the beak and an increasing fraction of the air is exhaled. The effect of this process is specific biphonation with two components having different fundamental frequencies ( $F$-component: $454.6 \pm 3.4 \mathrm{~Hz}$; $G$-component: $2542.1 \pm 30.2 \mathrm{~Hz}$ ). When the beak is opened only partially, the $F$-component is still strong, and the $G$-component sounds soft (Fig. 1, variant 3 ). In contrast, when the beak is fully opened, and no air is pumped back into the crop, $G$-component is very loud and contains sub-harmonics, which makes the sound harsh and eventually muffles the $F$-component (Fig. 1, variant 4$)$. The consecutive variants (1-4) were characterized by increasing amplitudes (Fig. 1—oscillograms).

Little Crake responded to treatments with four distinct call types, all consisting only of a single fundamental frequency (Fig. 2). All call types were characterized by a similar structure with multiple harmonics and small to moderate frequency modulation but differed in their temporal organization and amplitudes (Fig. 2-oscillograms). The softest calls resembled listless chatting and were produced in more or less regular series (chatting, Fig. 2a), whereas the loudest calls were typically produced in couples (so-called doublets, Fig. 2b). The remaining two types were easily distinguishable short series of peaks (calls in series: $1.8 \pm 0.15, n=321$; Fig. 2c) and long series of trills (calls in series: 19.2 \pm 4.53 , $n=27$; Fig. 2D). Such trills can be produced in series solo or in duets.

\section{Responses to treatments}

The two bird species responded differently to conspecific and heterospecific calls. Water Rails produced more individual and duet calls in response to the conspecific treatment (solo calls: $F_{1,200}=26.52, P<0.001$; duets: $F_{1,150}=4.45$, $P=0.04$; see Fig. 3a, b). However, duets did not include variant 1 calls and the proportion of louder call variants (V3 and V4) was higher in duets than in solos $\left(X^{2}{ }_{3}=22.53\right.$, $P<0.001)$. This difference in proportions was significant 
Table 1 Description of acoustic parameters used in the sound analysis

\begin{tabular}{|c|c|c|c|}
\hline \multirow[t]{2}{*}{ Parameter } & \multirow[t]{2}{*}{ Description } & \multicolumn{2}{|l|}{ Range } \\
\hline & & Water Rail & Little Crake \\
\hline$F 0[\mathrm{~Hz}]$ & Fundamental frequency & $210-609$ & $633-1887$ \\
\hline Peak [Hz] & Frequency at maximum power & $210-3680$ & $633-4219$ \\
\hline Q25 [Hz] & $\begin{array}{l}\text { Frequency that divides the } \\
\text { sound into two intervals } \\
\text { containing } 25 \% \text { and } 75 \% \text { of } \\
\text { the energy }\end{array}$ & 199-3398 & $609-2836$ \\
\hline Q75 [Hz] & $\begin{array}{l}\text { Frequency that divides the } \\
\text { sound into two intervals } \\
\text { containing } 75 \% \text { and } 25 \% \text { of } \\
\text { the energy }\end{array}$ & 410-3984 & $938-4125$ \\
\hline$\Delta F[\mathrm{~s}]$ & Duration of the call or & $0.08-2.29$ & \\
\hline$\Delta F+G[\mathrm{~s}]$ & component $^{\mathrm{a}}$ & $0.08-2.29$ & \\
\hline$\Delta[\mathrm{s}]$ & & & $0.02-0.09$ \\
\hline
\end{tabular}

${ }^{\text {a }} F$ and $G$ represent call components in the Water Rail—see Results for more details

only for the conspecific treatment $\left(X^{2}{ }_{3}=18.63, P<0.001\right)$, meaning it was not a by-product of the overall decrease of the number of softer call variants during this treatment. Furthermore, the acoustic structure of Water Rail calls differed between treatments (Fig. 4). During the conspecific treatment, the Water Rails called with lower fundamental frequency $\left(F_{1,128}=43.72, P<0.001\right.$; Fig. $\left.4 \mathrm{a}\right)$, higher peak frequency $\left(F_{1,130}=4.05, P=0.046\right.$; Fig. $\left.4 \mathrm{~b}\right)$, higher first quartile frequency $\left(F_{1,133}=3.13, P=0.079\right.$; Fig. $\left.4 c\right)$, and higher third quartile frequency $\left(F_{1,132}=4.68, P=0.032\right.$; Fig. 4 d), but with similar call duration $(\triangle F \cdot P=0.594$; $\Delta F+G \cdot P=0.249$; Figs. $4 \mathrm{e}$ ). At the same time, despite these differences, the fundamental frequency was correlated significantly with the peak and quartile frequencies $(F 0$ Peak: $r=-0.39, P<0.001 ; F 0-\mathrm{Q} 25: r=-0.43, P<0.001$; $F 0-Q 75: r=-0.41, P<0.001$; acronyms correspond to Table 1). Finally, Water Rails showed few attempts at direct action, with only three out of 52 birds (26 pairs) approaching the speaker (conspecific treatment $=3$, control $=0$ ).

Little Crakes also produced more calls in response to the conspecific treatment $\left(F_{1,184}=30.22, P<0.001\right.$; Fig. 5). All call types increased during the conspecific treatment except for chatting calls $\left(F_{3,184}=2.88, P=0.04\right.$; Fig. 5a), yet all but three series of trill (out of 23) were solos. Trills were only produced during the conspecific treatment, and in nine out of 12 cases by approaching birds $\left(X^{2}{ }_{1}=6.35, P=0.01\right)$. However, contrary to Water Rails, the acoustic structure of Little Crake calls differed marginally between treatments (Fig. 4). During the conspecific treatment, birds called with a higher third quartile frequency $\left(F_{1,243}=6.45, P=0.012\right.$; Fig. $\left.4 \mathrm{~d}\right)$, but this parameter was not correlated significantly with the fundamental frequency $(r=-0.044, P=0.49)$. Furthermore, and also in contrast to Water Rails, Little Crakes often approached the
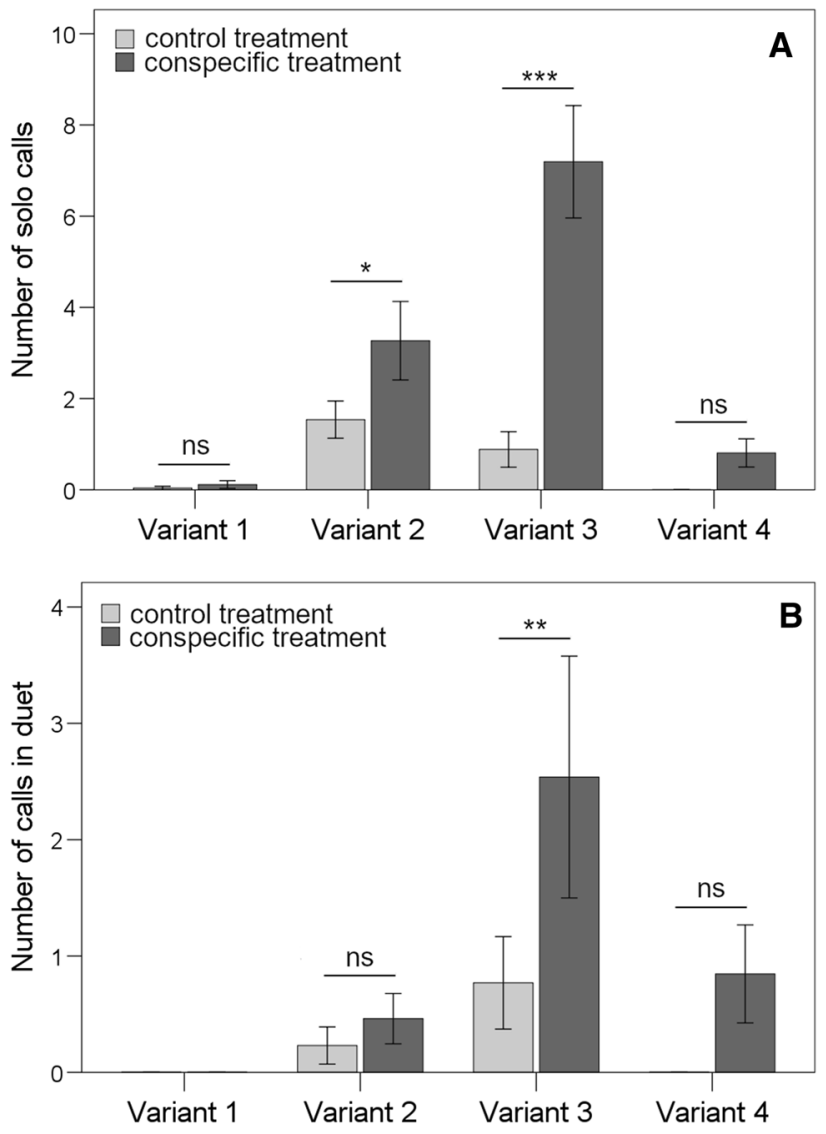

Fig. 3 Individual (a) and cooperative (b) vocal responses of Water Rails to conspecific and heterospecific (control) treatments. The boxes show mean \pm SE. Significant differences are indicated with symbols: $* P<0.05, * * P<0.01, * * * P<0.001 ; n s$ not significant

speaker (13 males and seven females/48 birds from 24 pairs). Approaches occurred more often and lasted longer during the conspecific treatment than during the heterospecific treatment (approach: $F_{1,94}=7.57, P=0.007$; length: $F_{1,94}=6.00$, $P=0.02$; Figs. 5b, c, respectively). Little Crakes were also more likely to approach the speaker alone than as a pair (16 vs. 2 cases; $\left.X^{2}{ }_{1}=6.41, P=0.01\right)$.

\section{Discussion}

Water Rails and Little Crakes both responded to conspecific calls but did so using distinct strategies. Water Rails increased the intensity of calling but disproportionately for louder call variants, while also producing more duets. They also modified the acoustic structure of their calls. However, they rarely approached the speaker, which suggests that Water Rails responded to territorial intrusion purely vocally. Little Crakes also increased the intensity of calling, but the increase was neither linked with the amplitude nor with the acoustic structure of calls as it was for the Water 

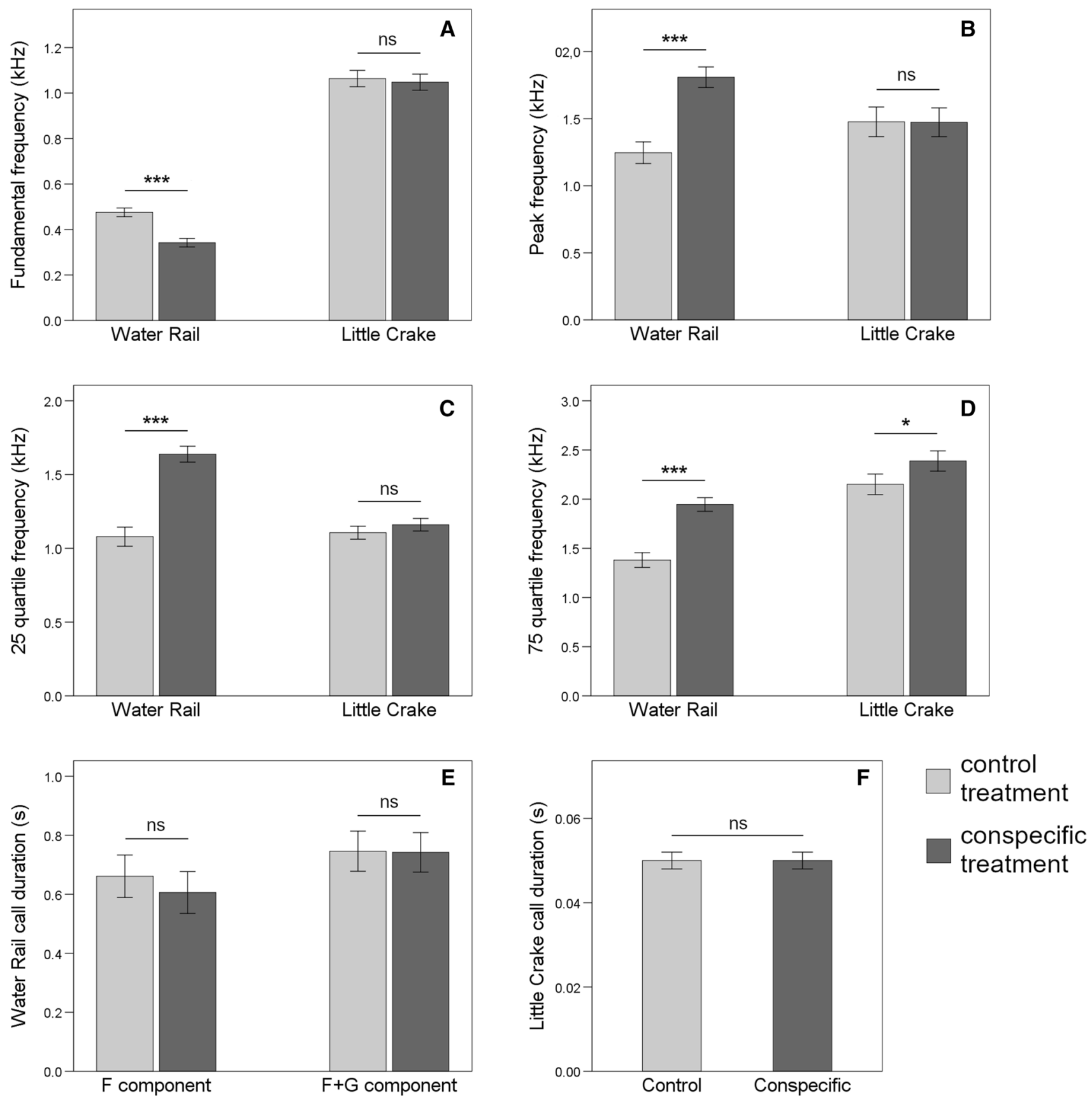

Fig. 4 Variability of structural (a-d) and temporal parameters (e, f) of Water Rail and Little Crake calls in relation to conspecific and heterospecific (control) treatments. The boxes show mean \pm SE. Sig-

nificant differences are indicated with symbols: $* P<0.05$, $* * P<0.01$, $* * * P<0.001 ; n s$ not significant

Rails. In contrast to Water Rails, Little Crakes frequently approached the speaker, suggesting that Little Crakes use both vocal signaling and direct action in response to the territorial intrusion. Overall, these differences in response demonstrate how two similar species and in the same habitat can develop differing adaptations for dealing with the territorial conflict settlement.

The territorial responses of Water Rails to conspecific playback come down to non-arbitrary changes in vocal behavior. Water Rails produced calls more frequently and louder in response to the conspecific treatment, suggesting a higher cost to defending their territory. However, these simple effects could be by-products of the caller's agitation, without any signaling implications. Call or song rate has 

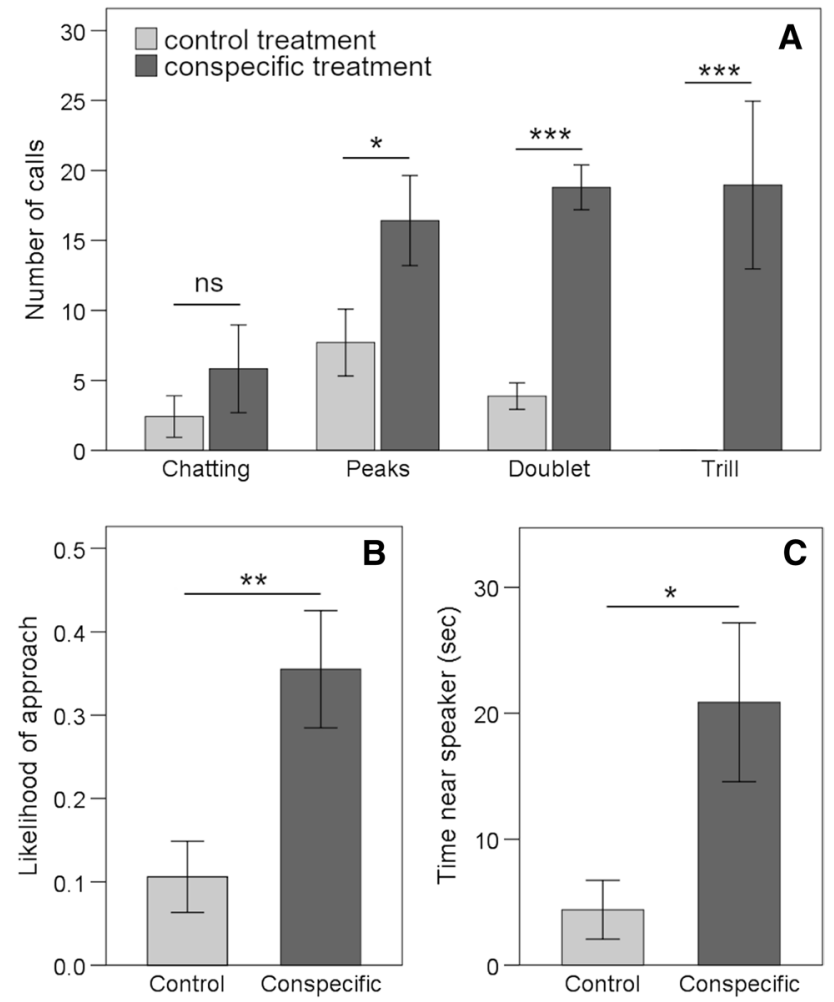

Fig. 5 Vocal (a) and non-vocal $(\mathbf{b}, \mathbf{c})$ responses of Little Crakes to conspecific and heterospecific (control) treatments. Because Little Crakes produced only three duets (out of 23 series), solo and duet calls were counted together. The boxes show mean \pm SE. Significant differences are indicated with symbols: ${ }^{*} P<0.05$, $* * P<0.01$, $* * * P<0.001 ; n s$ not significant

been frequently linked with energetic cost (Oberweger and Goller 2001; Hasselquist and Bensch 2008). Some studies challenge this view indicating that the production of vocalizations can be energetically cheap in relation to the overall daily energy budget (Ward et al. 2004). Similarly, call amplitude has a physical link with energy expenditure, but it could equally be assigned to the Lombard effect (Brumm and Zollinger 2011). Nonetheless, Water Rails also changed the structure of their calls. During both treatments, birds produced biphonal calls, which started with the low-frequency close-mouth $F$-component, followed by an openmouth high-frequency $G$-component. The fundamental frequency of the $F$-component decreased when birds responded to conspecific playbacks, whereas the $G$-component sounded higher. The closed-mouth calling allowed birds to achieve very low frequencies, suggesting that such behavior evolved specifically for this purpose. However, such a mechanism comes down to very low amplitudes, particularly in smaller birds (Ręk 2014; Riede et al. 2016). Therefore, most species do not communicate solely with low-frequency calls but accompany them with higher frequency components. In Water Rails, the spectral distribution of energy of the loud component was correlated with the fundamental frequency of the soft component. This suggests that receivers might acquire enough information to decide whether to escalate or retreat from a distance. Overall, these results suggest that some signal designs can be particularly useful in preventing fights, provided their production and transmission is controlled and substantiated with a robust and effective mechanism.

Water Rails duetted more often during the conspecific treatment, as expected for cooperative investment in territorial defense (Hall 2009). Avian duets are displays where two birds coordinate their vocalizations with a degree of temporal precision (Farabaugh 1982). Despite many reports (Taylor 1998), the duetting behavior has never been tested experimentally among the Rallidae. However, the clear alternation of the male and female calls seen in this study (Fig. 1b) implies that the joint calling of Water Rails was duetting. Furthermore, Water Rails used louder call variants (V3, V4) at a higher proportion in duets than in solo calls, suggesting that duets in Water Rails reflect the highest level of anxiety of the signalers. Therefore, irrespective of whether rail and passerine duets represent the same or different behaviors, both have many functional and structural similarities.

In contrast to the vocal response, Water Rails only exceptionally approached the speakers. The low number of Water Rails approaching the speaker during the experiment was reflected later in the low effectiveness of our trapping for that species, as opposed to the effectiveness of the same methods for Little Crakes. Similar low responsiveness was observed for the Ridgway's Rail (Rallus obsoletus) during call-count surveys (Bui et al. 2015). Reluctance to approach was likely not due to nest protection because incubating birds were observed leaving the nest to participate in duetting. Overall shyness is also not a reasonable explanation because the opposite behavior was observed for solitary males. At the beginning of the breeding season, solitary and presumably non-territorial males were frequently flying towards the loudspeaker, actively searching for the opponent (Authors' personal observations). This behavior ceased as soon as territories and pair bonds were established. This discrepancy suggests that aggression in the Water Rail is an offensive strategy aimed at obtaining a female and territory, but otherwise avoided in territorial defense. Therefore, as long as the playbacks did not threaten the birds directly, they could apply a less risky approach of signaling and waiting.

Similarly to Water Rails, Little Crakes increased calling in response to the conspecific playback, but they did not modify the acoustic structure of their calls like Water Rails. All Little Crake call types were open-mouthed and lacked the growling component found in the calls of Water Rails and other sympatric rallids, such as the Corncrake or Spotted 
Crake (Porzana porzana) (Ręk 2014, 2015). At the same time, apart from the purely quantitative effect, Little Crake calls remained surprisingly similar during both treatments. Calls had relatively high fundamental frequency (Table 1), which was not changed between treatments (Fig. 4). These acoustic and mechanistic limitations appear to be interconnected, suggesting that Little Crake calls have not evolved to preclude further aggressive escalation.

In addition to their differences in vocal signaling, Little Crakes were more likely to approach the speaker in response to conspecific calls and remain in close vicinity of the speaker than Water Rails. We observed that a typical approach by Little Crakes is accompanied by vocal signaling and, according to an earlier study, some threatening postures such as stretching of wings (Koenig 1943). The Little Crakes were observed to run around the speaker, jump up on to the speaker, and peck at it. We did not use any stuffed model, but earlier observations suggest that would end with a physical attack towards the model (Koenig 1943). These observations suggest that some form of direct action, in the form of physical aggression, is an inherent part of Little Crake's territorial strategy.

In conclusion, our study showed that territorial aggression and signaling does not necessarily reflect species behavior in other contexts and its morphology. In our experiment, both Water Rails and Little Crakes were in a privileged position as territory holders, which means that they neither had to call nor to approach. However, despite this initial standardization species responded differently; Water Rails applied a costly signaling strategy, whereas Little Crakes relied more on direct actions. We suggest that even if such differences might appear counterintuitive, they are justified evolutionarily. Aggression is common when the risk of injury is low, whereas costly signaling is used to supplements aggression when the risk is high.

Acknowledgements We thank Tomasz Osiejuk and to two anonymous referees for valuable comments on the manuscript.

Author contributions JJ, MP, and PR conceived the ideas and designed methodology. JJ, and MP collected data. JJ, MB, and PR analyzed the data. JJ, and PR led the writing of the manuscript. All authors read and approved the final manuscript.

Funding The study was carried out at the Biological and Chemical Research Centre, University of Warsaw, established within the project co-financed by European Union from the European Regional Development Fund under the Operational Programme Innovative Economy, 2007-2013. This work was supported by the National Science Centre in Poland (Grant number 2014/15/N/NZ8/00337).

Data availability The data used in this study are available from the corresponding authors upon request.

\section{Compliance with ethical standards}

Conflict of interest Not applicable.

Ethical approval The study complied with the ASAB/ABS guidelines for the use of animals in research and fulfilled the current Polish law. The research was approved by the Regional Directorate for Environmental Protection (approval number WOPN-OOP.6401.28.2016EK).

Open Access This article is licensed under a Creative Commons Attribution 4.0 International License, which permits use, sharing, adaptation, distribution and reproduction in any medium or format, as long as you give appropriate credit to the original author(s) and the source, provide a link to the Creative Commons licence, and indicate if changes were made. The images or other third party material in this article are included in the article's Creative Commons licence, unless indicated otherwise in a credit line to the material. If material is not included in the article's Creative Commons licence and your intended use is not permitted by statutory regulation or exceeds the permitted use, you will need to obtain permission directly from the copyright holder. To view a copy of this licence, visit http://creativecommons.org/licenses/by/4.0/.

\section{References}

Ali S, Anderson R (2018) Song and aggressive signaling in Bachman's Sparrow. Auk 135:521-533

Arnott G, Elwood RW (2008) Information gathering and decision making about resource value in animal contests. Anim Behav 76:529-542

Barry P (1995) Water Rail stabbing a Common Snipe. Br Birds $88: 224$

Bengtson SA (1967) Territoriality in Water Rail (Rallus aquaticus) in early spring. Var Fagelvarld 26:6-18

Bergman M, Olofsson M, Wiklund C (2010) Contest outcome in a territorial butterfly: the role of motivation. Proc R Soc B Biol Sci 277:3027-3033

Bradbury JW, Vehrencamp SL (2011) Principles of animal communication. Sinauer Associates Inc, Sunderland

Brumm H, Zollinger SA (2011) The evolution of the Lombard effect: 100 years of psychoacoustic research. Behaviour 148:1173-1198

Bui T-VD, Takekawa JY, Overton CT et al (2015) Movements of radiomarked California Ridgway's Rails during monitoring surveys: implications for population monitoring. J Fish Wildl Manag 6:227-237

Ceccobelli S, Battisti C (2010) On the water depth in diving sampling sites of Tachybaptus ruficollis. Rend Fis Acc Lincei 21:359-364

Ciach M (2007) Interference competition between rails and crakes (Rallidae) during foraging in the post-breeding season. Turkish J Zool 31:161-163

Copenhaver C, Ewald PW (1980) Cost of territory establishment in hummingbirds. Oecologia 46:155-160

Côté SD (2000) Aggressiveness in King Penguins in relation to reproductive status and territory location. Anim Behav 59:813-821

Craig JL (1977) The behaviour of the Pukeko, Porphyrio porphyrio melanotus. New Zeal J Zool 4:413-433

Cramp S, Simmons KEL (1980) Handbook of the birds of Europe, the Middle East and North Africa, vol 2. Oxford University Press, Oxford, Hawks to bustards 
de Kort SR, Eldermire ERB, Cramer ERA, Vehrencamp SL (2009) The deterrent effect of bird song in territory defense. Behav Ecol 20:200-206

Dittberner H, Dittberner W (1990) Öko-ethologische beobachtungen am nest der Kleinralle (Porzana parva). Bonner Zool Beiträge 41:27-58

Enquist M (1985) Communication during aggressive interactions with particular reference to variation in choice of behavior. Anim Behav 33:1152-1161

Enquist M, Leimar O (1990) The evolution of fatal fighting. Anim Behav 39:1-9

Farabaugh SM (1982) The ecological and social significance of duetting. In: Kroodsma DE, Miller EH (eds) Acoustic communication in birds, vol 2. Academic Press, New York, pp 85-124

Fitch WT (1999) Acoustic exaggeration of size in birds via tracheal elongation: comparative and theoretical analyses. J Zool 248:31-48

Garcelon DK (1990) Observations of aggressive interactions by Bald Eagles of known age and sex. Condor 92:532-534

Goller F, Riede T (2013) Integrative physiology of fundamental frequency control in birds. J Physiol Paris 107:230-242

Hall ML (2009) A review of vocal duetting in birds. Adv Study Behav 40:67-121

Hand JL (1986) Territory defense and associated vocalizations of Western Gulls. J F Ornithol 57:1-15

Hansen AJ (1986) Fighting behavior in Bald Eagles: a test of game theory. Ecology 67:787-797

Hasselquist D, Bensch S (2008) Daily energy expenditure of singing Great Reed Warblers Acrocephalus arundinaceus. J Avian Biol 39:384-388

Hurd PL (2006) Resource holding potential, subjective resource value, and game theoretical models of aggressiveness signalling. J Theor Biol 241:639-648

Jedlikowski J, Brambilla M (2017) Effect of individual incubation effort on home range size in two rallid species (Aves: Rallidae). J Ornithol 158:327-332

Jedlikowski J, Chibowski P, Karasek T, Brambilla M (2016) Multiscale habitat selection in highly territorial bird species: exploring the contribution of nest, territory and landscape levels to site choice in breeding rallids (Aves: Rallidae). Acta Oecologica 73:10-20

Jemieson IG (1997) Testing reproductive skew models in a communally breeding bird, the pukeko, Porphyrio porphyrio. Proc R Soc B Biol Sci 264:335-340

Kaiser A, Merckx T, Van Dyck H (2019) Personality traits influence contest outcome, and vice versa, in a territorial butterfly. Sci Rep 9:2778

Kasumovic MM, Elias DO, Punzalan D, Mason AC, Andrade MCB (2009) Experience affects the outcome of agonistic contests without affecting the selective advantage of size. Anim Behav $77: 1533-1538$

King B (1980) Individual recognition and winter behaviour of Water Rail. Br Birds 73:33-35

Koenig O (1943) Rallen und bartmeisen. Niederdona, Vienna

Krebs JR (1982) Territorial defence in the Great Tit (Parus major): do residents always win? Behav Ecol Sociobiol 11:185-194

Low M (2006) The energetic cost of mate guarding is correlated with territorial intrusions in the New Zealand stitchbird. Behav Ecol 17:270-276

Marler P (2004) Bird calls: a cornucopia for communication. In: Marler P, Slabbekoorn H (eds) Nature's music: the science of birdsong. Elsevier Academic Press, San Diego, pp 132-177

McGregor PK (1993) Signalling in territorial systems: a context for individual identification, ranging and eavesdropping. Philos Trans R Soc B 340:237-244
Millar RB, Anderson MJ (2004) Remedies for pseudoreplication. Fish Res 70:397-407

Oberweger K, Goller F (2001) The metabolic cost of birdsong production. J Exp Biol 204:3379-3388

Pandolfi M, D'Astore PRP (1992) Aggressive behaviour in Montagu's Harrier (Circus pygargus) during the breeding season. Ital J Zool 59:57-61

Penteriani V, Del Mar DM, Alonso-Alvarez C, Sergio F (2007) The importance of visual cues for nocturnal species: eagle owls signal by badge brightness. Behav Ecol 18:143-147

Pierotti R, Annett C (1994) Patterns of aggression in gulls: asymmetries and tactics in different social categories. Condor 96:590-599

Piper WH, Walcott C, Mager JN, Spilker FJ (2008) Fatal battles in common loons: a preliminary analysis. Anim Behav $75: 1109-1115$

Podos J, Nowicki S (2004) Performance limits on birdsong. In: Marler P, Slabbekoorn H (eds) Nature's music: the science of birdsong. Elsevier Academic Press, San Diego, pp 318-342

Polak M (2005) Temporal pattern of vocal activity of the Water Rail Rallus aquaticus and the Little Crake Porzana parva in the breeding season. Acta Ornithol 40:21-26

Ręk P (2014) Do aggressive signals evolve towards higher reliability or lower costs of assessment? J Evol Biol 27:2605-2613

Ręk P (2015) High functional complexity despite an extremely small repertoire of calls in the Spotted Crake (Porzana porzana). Auk 132:613-623

Ręk P, Osiejuk TS (2011) Nonpasserine bird produces soft calls and pays retaliation cost. Behav Ecol 22:657-662

Ręk P, Osiejuk TS (2013) Temporal patterns of broadcast calls in the Corncrake encode information arbitrarily. Behav Ecol 24:547-552

Riede T, Eliason CM, Miller EH, Goller F, Clarke JA (2016) Coos, booms, and hoots: the evolution of closed-mouth vocal behavior in birds. Evolution (N Y) 70:1734-1746

Searcy WA, Nowicki S (2005) The evolution of animal communication: reliability and deception in signaling systems. Princeton University Press, Princeton

Searcy WA, Beecher MD (2009) Song as an aggressive signal in songbirds. Anim Behav 78:1281-1292

Searcy WA, Anderson RC, Nowicki S (2006) Bird song as a signal of aggressive intent. Behav Ecol Sociobiol 60:234-241

Searcy WA, Anderson RC, Ballentine B, Nowicki S (2013) Limits to reliability in avian aggressive signals. Behaviour 150:1129-1145

Severinghaus LL (2008) Territoriality and the significance of calling in the Lanyu Scops Owl Otus elegans botelensis. Ibis 142:297-304

Sih A, Bell A, Johnson JC (2004) Behavioral syndromes: an ecological and evolutionary overview. Trends Ecol Evol 19:372-378

Steiof K (1999) Water Rail killing and eating wader. Br Birds 92:204

Suthers RA (1990) Contributions to birdsong from the left and right sides of the intact syrinx. Nature 347:473-477

Taylor PB (1998) Rails: a guide to the rails, crakes, gallinules and coots of the world. Pica Press, Sussex

Temeles EJ (1990) Northern harriers on feeding territories respond more aggressively to neighbors than to floaters. Behav Ecol Sociobiol 26:57-63

Vehrencamp SL, Ellis JM, Cropp BF, Koltz JM (2014) Negotiation of territorial boundaries in a songbird. Behav Ecol 25:1436-1450

Waas JR (1991) The risks and benefits of signalling aggressive motivation: a study of cave-dwelling Little Blue Penguins. Behav Ecol Sociobiol 29:139-146

Ward S, Lampe HM, Slater PJB (2004) Singing is not energetically demanding for Pied Flycatchers, Ficedula hypoleuca. Behav Ecol $15: 477-484$

Publisher's Note Springer Nature remains neutral with regard to jurisdictional claims in published maps and institutional affiliations. 